\title{
Highly Multifunctional and Thermoconductive Performances of Densely Filled Boron Nitride Nanosheets/Epoxy Resin Bulk Composites
}

Kun $\mathrm{Fu}^{a, b}$, Jingwen Yang ${ }^{a, b}$, Chaochao Cao ${ }^{a, b}$, Qinghong Zhai ${ }^{a, b}$, Wei Qiao ${ }^{a, b}$, Jiaxiao Qiao ${ }^{a, b}$, Hejun Gao ${ }^{a, b}$, Zheng Zhou ${ }^{a, b}$, Jiawei Ji ${ }^{a, b}$, Mengyuan Li ${ }^{a, b}$, Chaoze Liu $^{a, b}$, Bozheng Wang ${ }^{a, b}$, Wenjuan Bai ${ }^{a, b}$, Hongliang Duan ${ }^{a, b}$, Yanming Xue ${ }^{a, b}$, *, Chengchun Tang ${ }^{a, b, *}$

${ }^{\text {a }}$ School of Materials Science and Engineering, Hebei University of Technology, Tianjin 300130, P. R. China

${ }^{\mathrm{b}}$ Hebei Key Laboratory of Boron Nitride Micro and Nano Materials, Hebei University of Technology, Tianjin 300130, P.R. China

*Corresponding Author'E-mail: ym.xue@hebut.edu.cn; tangcc@hebut.edu.cn 


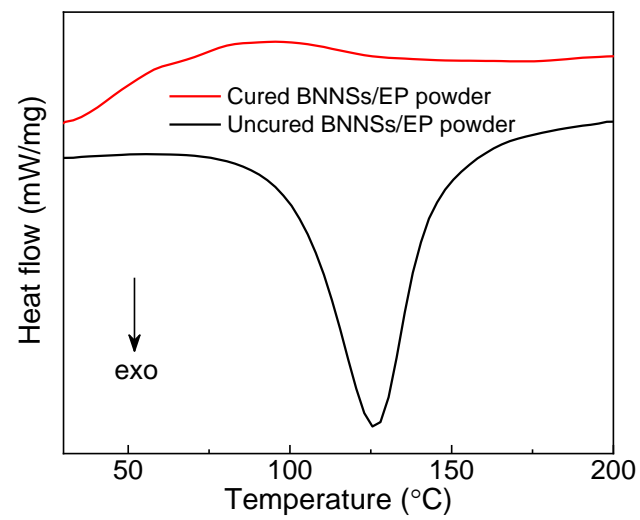

Figure S1. The heat flow curves of uncured and cured BNNSs/EP powders were measured by a differential scanning calorimeter (DSC). 

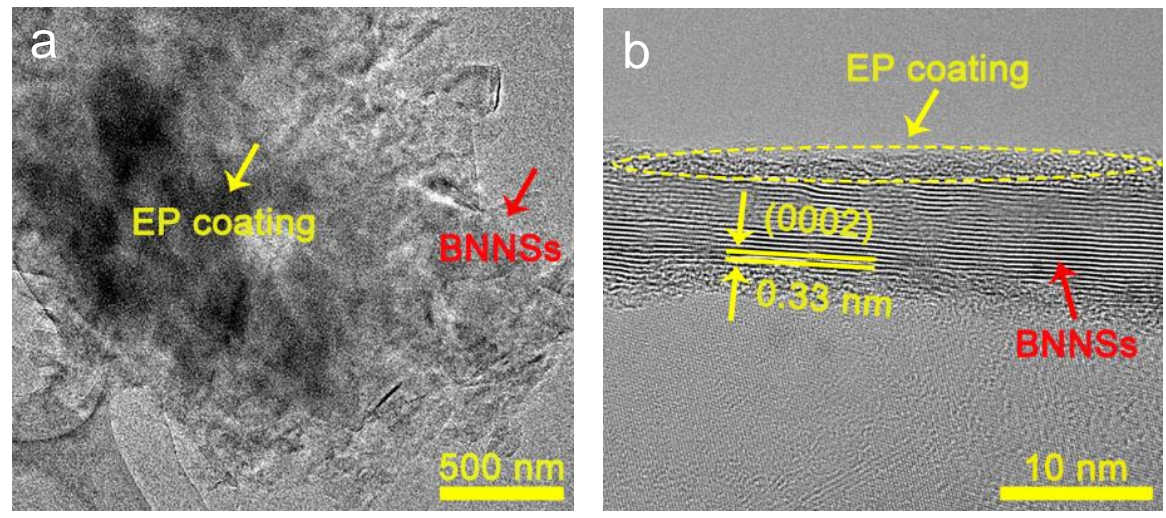

Figure S2. (a) TEM image and (b) HRTEM image of uncured BNNSs/EP powder. The yellow circle marked was the EP thin layer, and the red arrow pointed towards the BNNSs. 

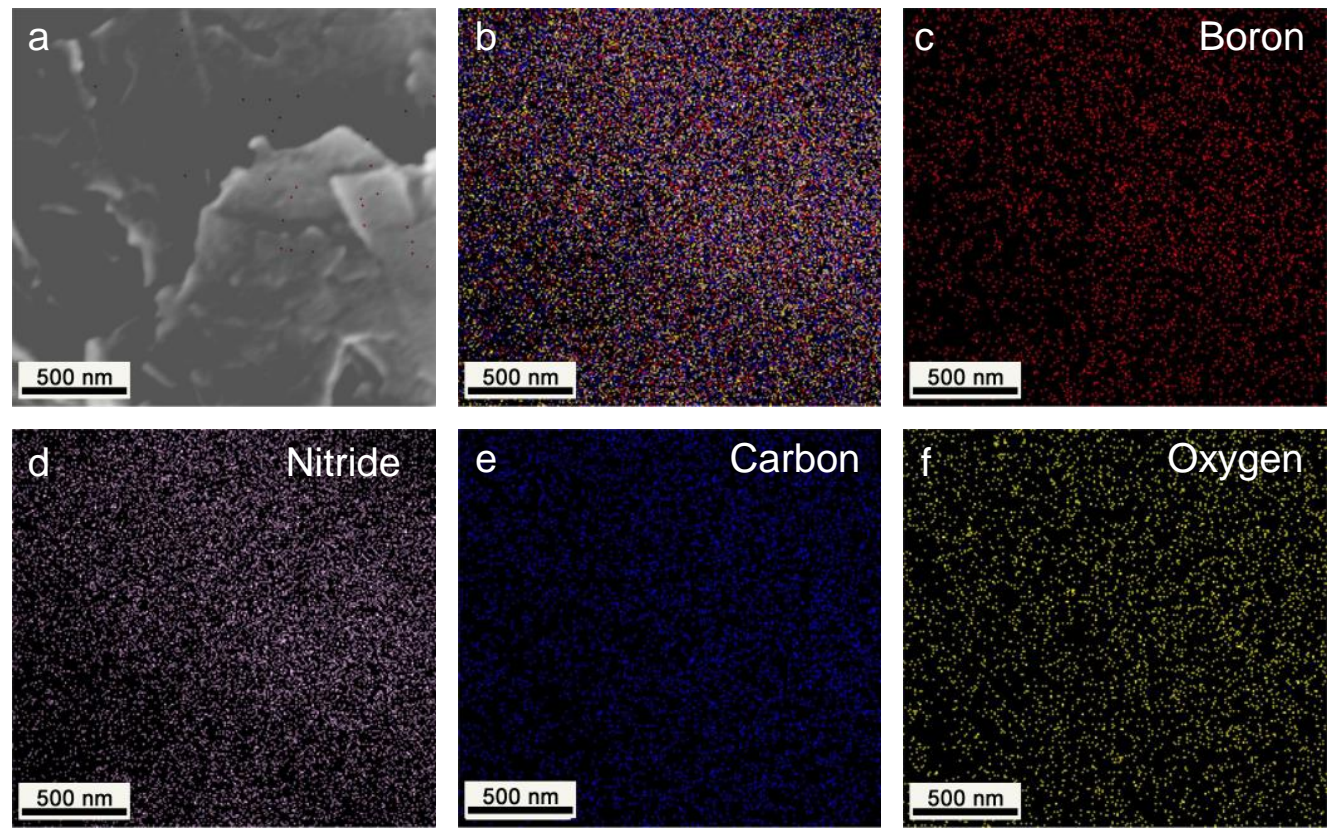

Figure S3. (a) SEM image of the uncured BNNSs/EP powder. (b) An overlay of boron, nitrogen, carbon and oxygen elemental mappings of the EDS region corresponding to the Figure S3a. (c, d) The individual spatially-resolved distribution of boron and nitrogen element mappings corresponding to the distribution of BNNSs. (e, f) Carbon and oxygen element mappings representing the distribution of EP in BNNS's surface. 
a

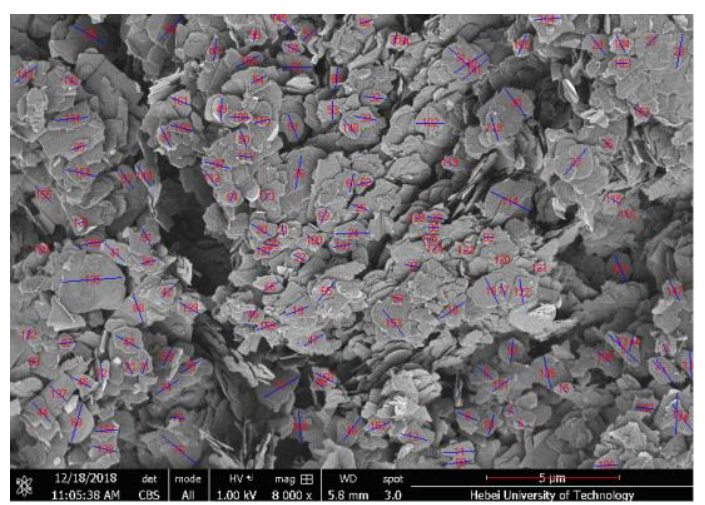

b

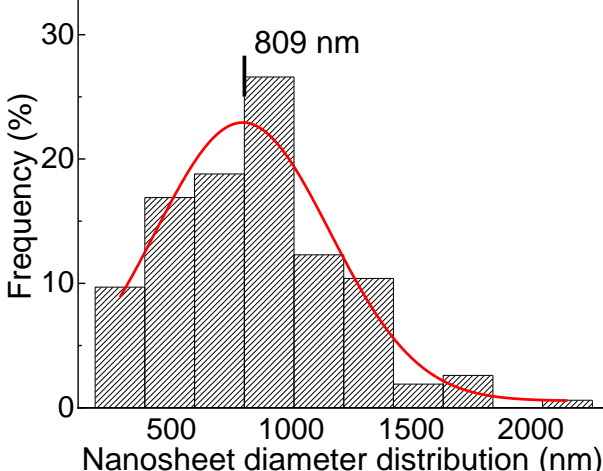

Figure S4. (a) SEM image of the BNNSs. (b)Statistical distribution of the nanosheets' lateral sizes. 


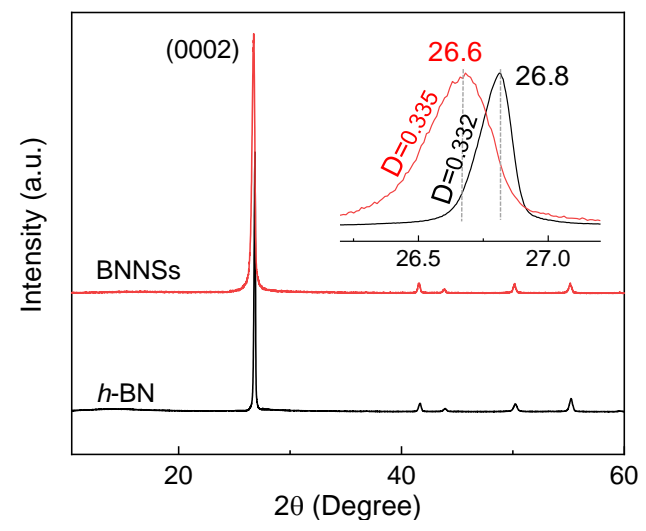

Figure S5. Statistical distribution of the $h$-BN and nanosheets' thicknesses was calculated by Debye-Scherrer formula $\mathrm{D}=\frac{K * \gamma}{\beta * \cos \theta}$, as a result, the average thickness is $\sim 73 \mathrm{~nm}$ and $\sim 35 \mathrm{~nm}$, respectively. 


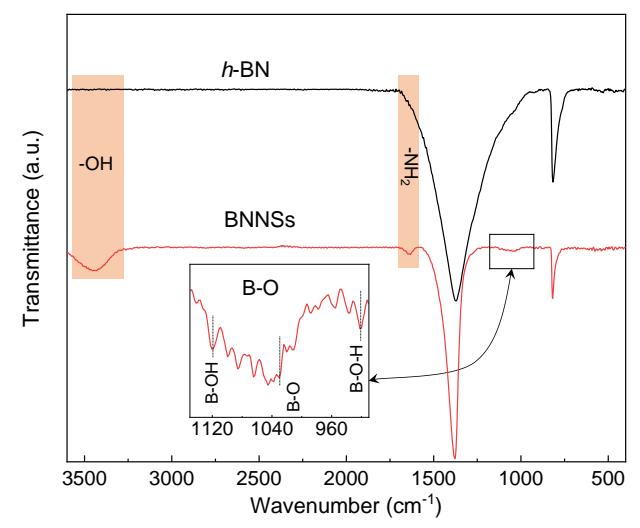

Figure S6. FT-IR spectra of the $h$-BN and BNNSs. 


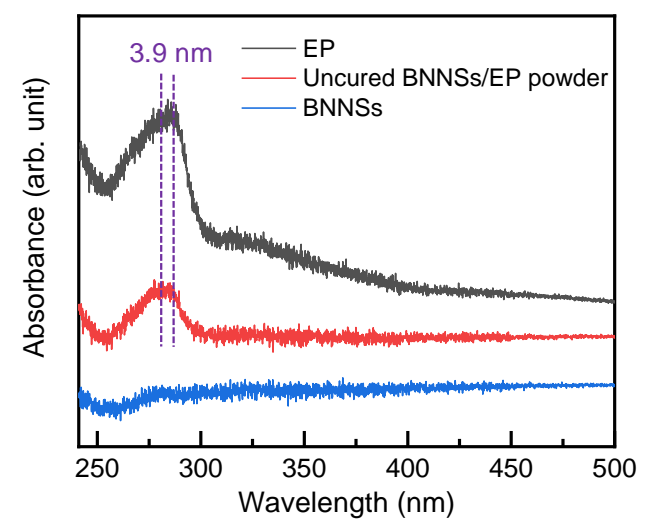

Figure S7. UV-vis spectra result for the EP, BNNSs and uncured BNNSs/EP powders. 

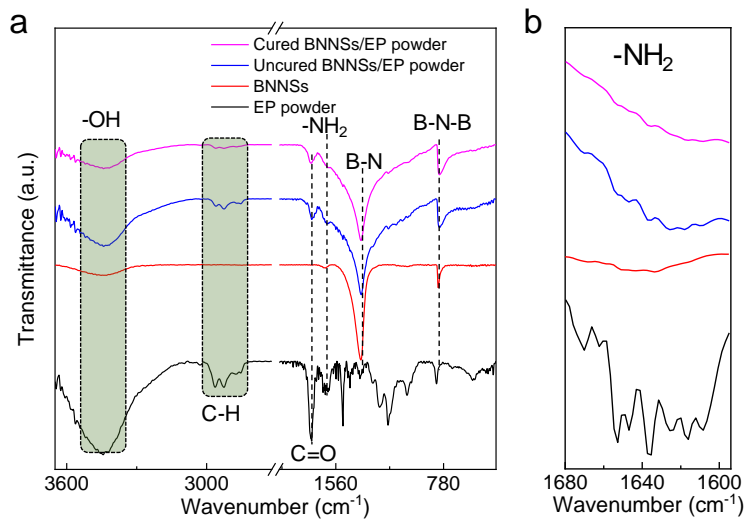

Figure S8. (a) FT-IR spectra of the BNNSs, EP, uncured BNNSs/EP and cured BNNSs/EP powders. (b) The enlarged range from the FT-IR spectra of Figure S8a. 


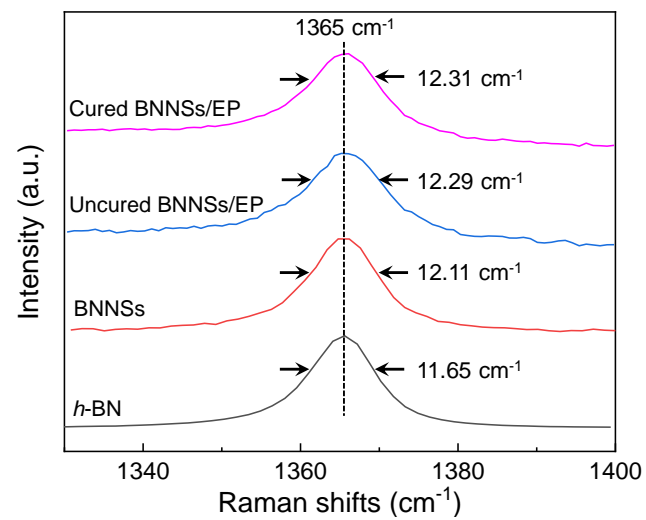

Figure S9. Raman spectra of the $h$-BN, BNNSs, uncured and cured BNNSs/EP powders. 

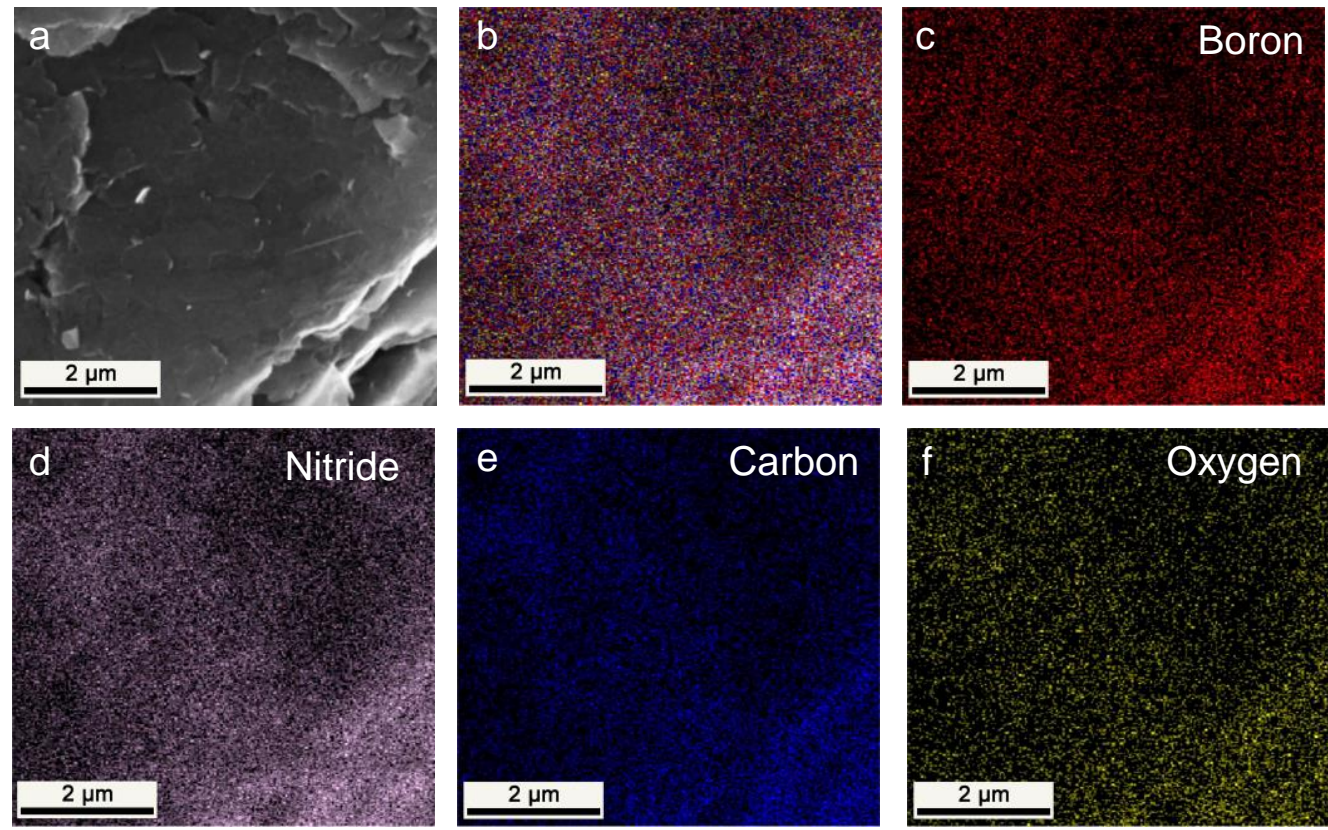

Figure S10. (a) The SEM image for fracture surface of the cured BNNSs/EP composite along with the in-plane direction. (b) An overlay of boron, nitrogen, carbon and oxygen elemental mappings of the EDS region corresponding to the Figure S10a. (c, d) The individual spatially-resolved distribution of boron and nitrogen element mappings corresponding to the distribution of BNNSs. (e, f) Carbon and oxygen element mappings representing the distribution of EP in BNNS's surface. 

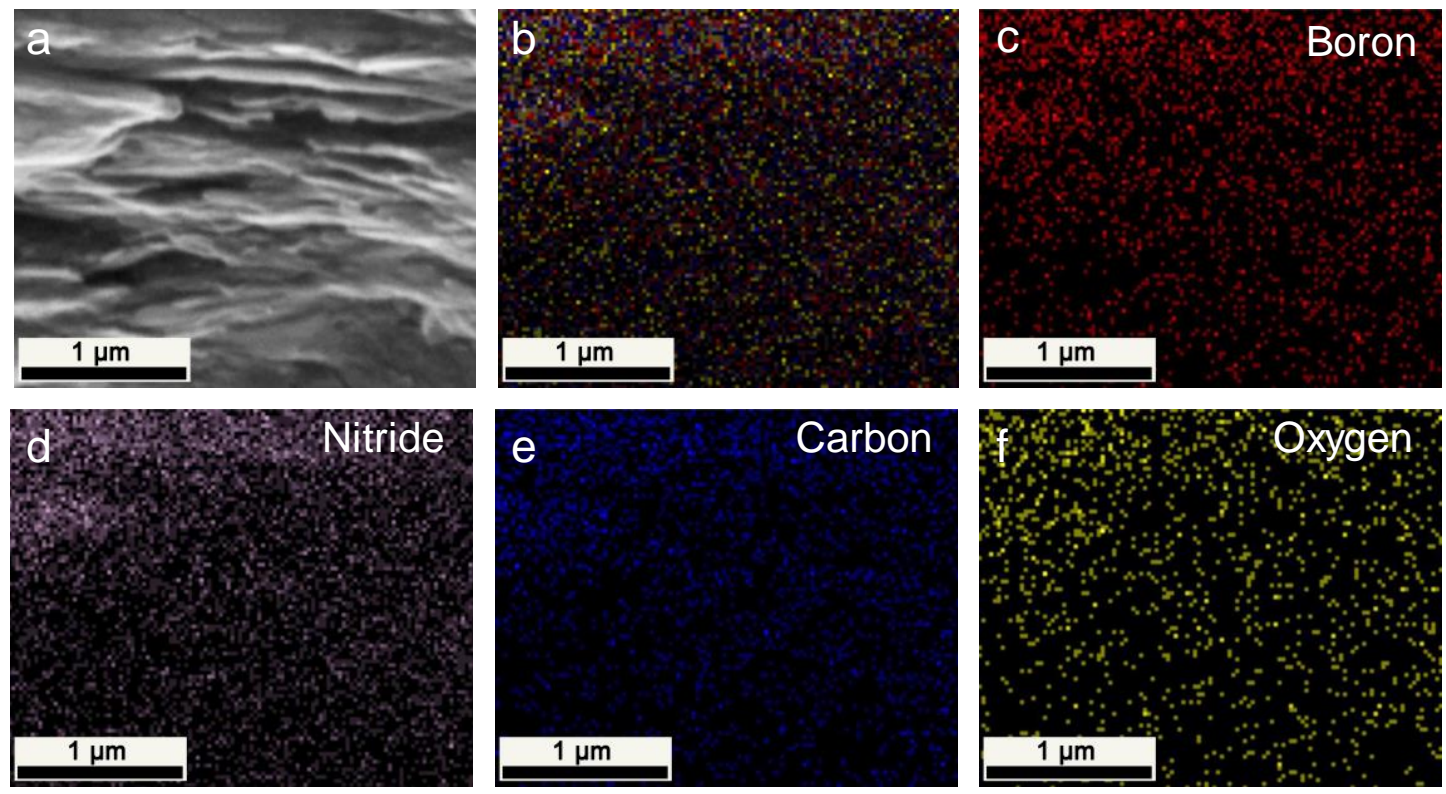

Figure S11. (a) The SEM image for fracture surfaces of the cured BNNSs/EP composite along with the out-of-plane direction. (b) An overlay of boron, nitrogen, carbon and oxygen elemental mappings of the EDS region corresponding to the Figure S11a. (c, d) The individual spatially-resolved distribution of boron and nitrogen element mappings corresponding to the distribution of BNNSs. (e, f) Carbon and oxygen element mappings representing the distribution of EP in BNNS's surface. 

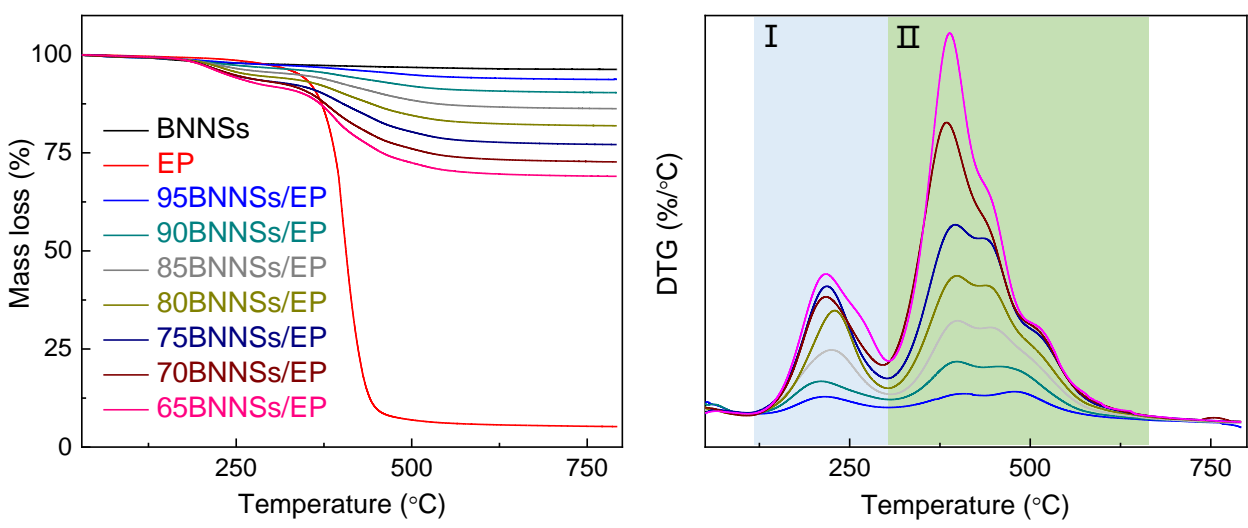

Figure S12. (a) TG curves of BNNSs, EP and BNNSs/EP bulk composites. (b) DTG curves of BNNSs/EP bulk composites.

NOTE: The BNNSs show a weight-loss of $3.7 \%$, which can be attributed to the decomposition of grafted $\mathrm{B}-\mathrm{O}-\mathrm{H}, \mathrm{B}-\mathrm{O}, \mathrm{B}-\mathrm{OH}$, and $-\mathrm{NH}_{2}$ at $170-470{ }^{\circ} \mathrm{C}$. The components of pure epoxy resin decomposed at $280-600{ }^{\circ} \mathrm{C}$, whereas two significant drops can be found from the DTG curve of BNNSs/EP composites. The first stage occurs at about $125-300{ }^{\circ} \mathrm{C}$, which is caused by the pyrolysis of low molecular weight components that failed to participate in the crosslinking reaction. The second stage at about $300-650{ }^{\circ} \mathrm{C}$ is attributed to the decomposition of the main chain of the cured epoxy resin. Up to this, all organic compounds were completely decomposed and volatilized. Therefore, the content of BNNSs in the composites can be calculated from the TG curves, and the mass fraction is $97.4 \%, 93.8 \%, 89.9 \%, 86.2 \%, 80.7 \%, 75.8 \%$ and $72.9 \%$, respectively. 

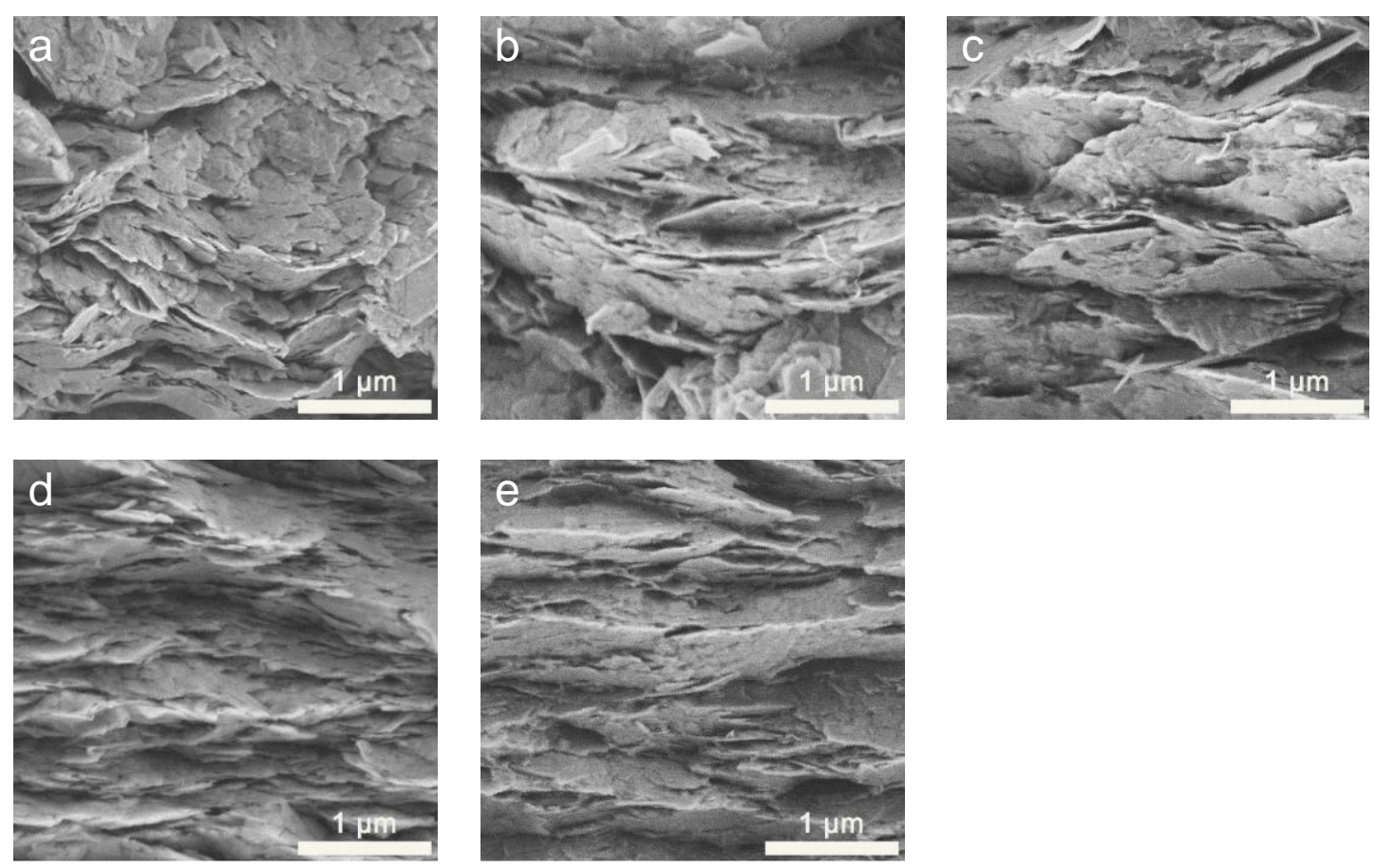

Figure S13. Cross-section SEM images of composites with different BNNSs loading. (a) $65 \mathrm{BNNSs} / \mathrm{EP}$; (b) $75 \mathrm{BNNSs} / \mathrm{EP}$; (c) $85 \mathrm{BNNSs} / \mathrm{EP}$; (d) $90 \mathrm{BNNSs} / \mathrm{EP}$; (e) 95BNNSs/EP. 


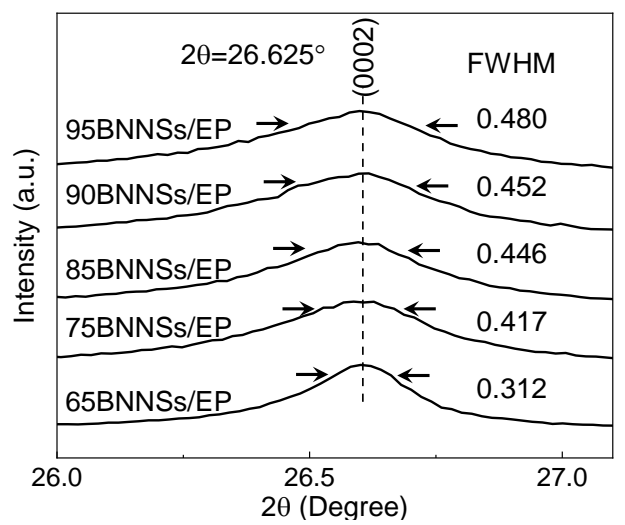

Figure S14. Enlargement of the (0002) pattern in the XRD of various BNNSs/EP bulk composites. 
Table S1. Experimental data derived from (0002) diffraction peaks for all investigated BNNSs/EP composites.

\begin{tabular}{lccccc}
\hline & $\begin{array}{c}\text { FWHM } \\
(\boldsymbol{\beta})\end{array}$ & $\boldsymbol{\theta}$ & $\boldsymbol{K}$ & $\boldsymbol{\lambda}$ & $\boldsymbol{D}$ \\
\hline 95BNNS/EP & 0.480 & 26.6 & 0.89 & 0.15405 & 22.349 \\
90BNNS/EP & 0.452 & 26.6 & 0.89 & 0.15405 & 23.733 \\
85BNNS/EP & 0.446 & 26.6 & 0.89 & 0.15405 & 24.052 \\
75BNNS/EP & 0.417 & 26.6 & 0.89 & 0.15405 & 25.725 \\
65BNNS/EP & 0.312 & 26.6 & 0.89 & 0.15405 & 34.383 \\
\hline
\end{tabular}

NOTE: The thickness (D) of BNNSs in the composites was calculated by DebyeScherrer formula: $\mathrm{D}=\frac{K * \gamma}{\beta * \cos \theta}$ using JADE software. FWHM $(\beta)$ and $\theta$ were the full width at half-maximum and diffraction angle of (0002) peak in the XRD pattern of the bulk composites, respectively. K and $\gamma$ were Scherrer constant and X-ray wavelength, respectively. 


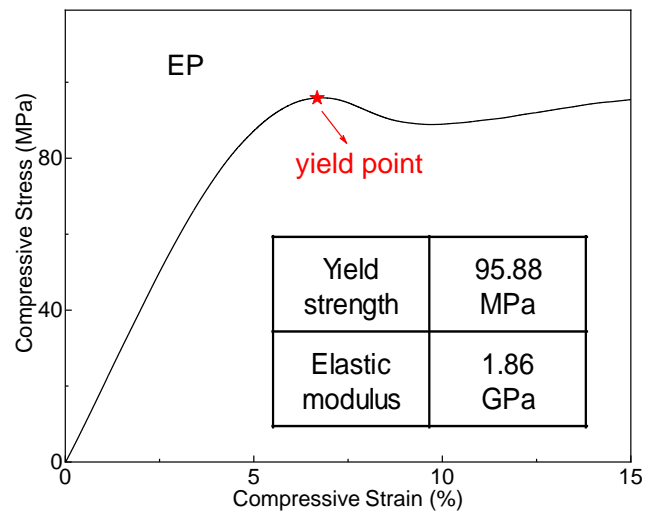

Figure S15. Representative compressive stress-strain curve of pure EP, inset shows the yield strength and elastic modulus of pure EP. 

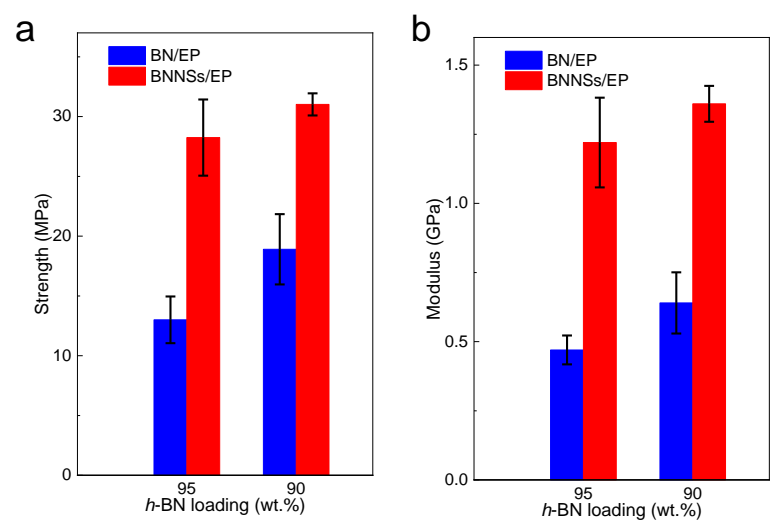

Figure S16. Statistic histograms of (a) compression strength and (b) modulus of 90BNNSs/EP, 95BNNSs/EP, 90BN/EP and 95BN/EP composites. It is obvious that the strengths and modulus of BNNSs/EP was better than those of the BN/EP. 


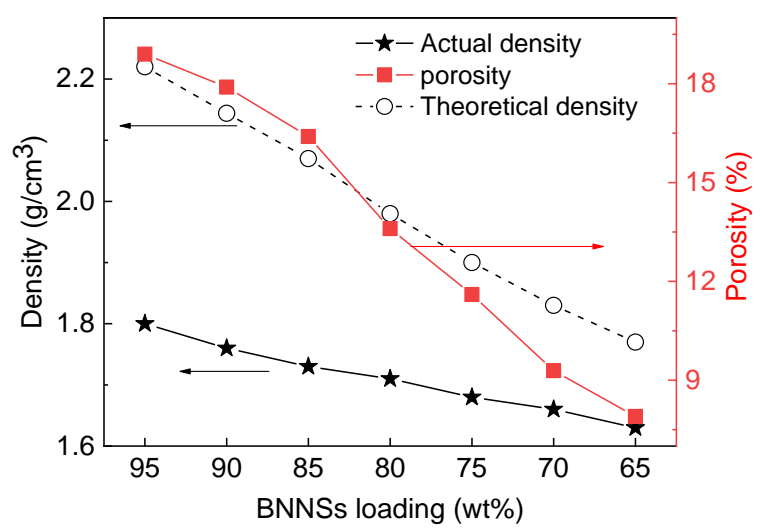

Figure S17. Actual density, theoretical density and porosity of the BNNSs/EP composites with different BNNSs contents.

NOTE: The porosity $(\phi)$ was defined as $\phi=1-\rho / \rho_{\text {theory }}$, where $\rho$ and $\rho_{\text {theory }}$ were actual density and density in theory of specimen, respectively. The $\rho$ of the composites with $\rho$ $=\mathrm{m} / \mathrm{v}$, in which $\mathrm{m}$ and $\mathrm{v}$ were the mass and volume of the composites, respectively. The $\rho_{\text {theory }}$ of the composites with $\rho_{\text {theory }}=1 /\left(\mathrm{m}_{\text {BNNSs }} / \rho_{\text {BNNSs }}+\mathrm{m}_{\text {ep }} / \rho_{\text {ep }}\right)$, in which $\mathrm{m}_{\text {BNNSs }}$ and $\mathrm{m}_{\mathrm{ep}}$ were the theory mass of BNNSs and EP in composites, and $\rho_{\mathrm{BNNSs}}$ and $\rho_{\mathrm{ep}}$ were the theory densities of BNNSs and EP. 


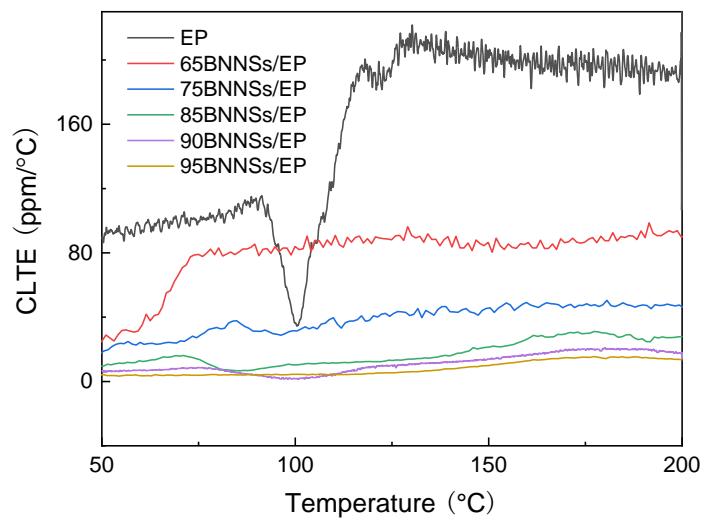

Figure S18. Temperature-dependent plots for the coefficient of linear thermal expansion (CLTE) of the pure EP and various BNNSs/EP composites. 


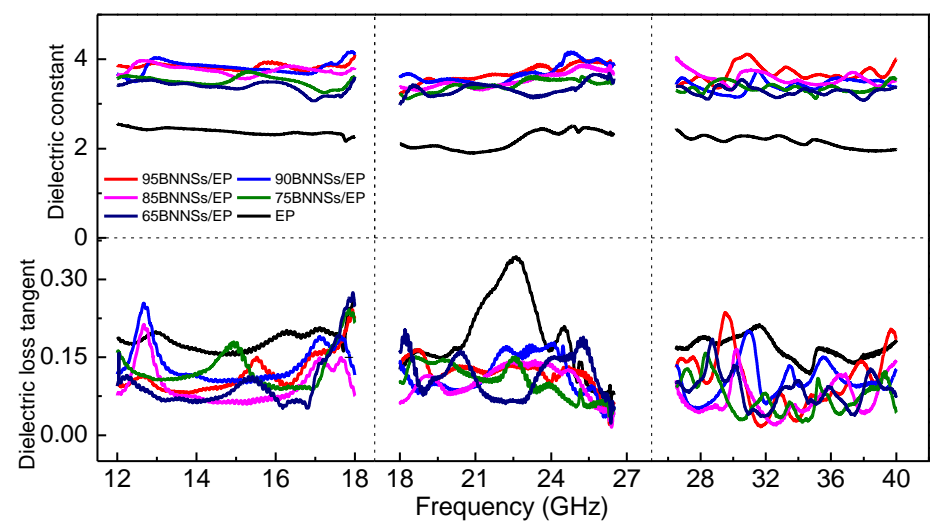

Figure S19. Frequency-dependent dielectric constant and loss tangent of the pure EP and BNNSs/EP composites with the measured frequency range of 12 - $40 \mathrm{GHz}$. 
Table S2. Summarization of DC and DLT of the EP polymer composites filled with carbon materials and inorganic thermal conductive particles, compared with our BNNSs/EP bulk composites.

\begin{tabular}{|c|c|c|c|c|c|}
\hline \multirow{2}{*}{ Composites } & \multirow{2}{*}{$\begin{array}{l}\text { Frequency } \\
\qquad(\mathrm{GHz})\end{array}$} & \multirow{2}{*}{$\begin{array}{c}\text { Loading } \\
\text { (wt.\%) }\end{array}$} & \multicolumn{2}{|c|}{ Dielectric properties } & \multirow{2}{*}{ References } \\
\hline & & & DC & DLT & \\
\hline SMF-RGO/EP & $12-18$ & 0.9 & $\sim 4.5-5.0$ & - & [S1] \\
\hline MWCNT/EP & $12-26.5$ & 10 & $\sim 13-18$ & $\sim 2-6.5$ & [S2] \\
\hline MWCNT/EP & $12-20$ & 10 & $\sim 7.6-8.2$ & $0.14-0.24$ & [S3] \\
\hline NT-Graphite/EP & $12-18$ & 9 & $\sim 10$ & - & [S4] \\
\hline Exfoliate Graphite/EP & $12-18$ & 40 & $\sim 27-35$ & $\sim 0.3-0.36$ & [S5] \\
\hline $\mathrm{PeF}-\mathrm{SiC} / \mathrm{EP}$ & $12-18$ & 50 & $\sim 4-5.5$ & $\sim 0.46-0.64$ & [S6] \\
\hline $\mathrm{BiF}-\mathrm{SiC} / \mathrm{EP}$ & $12-18$ & 50 & $\sim 3.5-4.7$ & $\sim 0.45-0.64$ & [S6] \\
\hline TrF-SiC/EP & $12-18$ & 50 & $\sim 3.8-4.5$ & $\sim 0.38-0.47$ & [S6] \\
\hline QuF-SiC/EP & $12-18$ & 50 & $\sim 3.1-4.2$ & $\sim 0.68-0.76$ & [S6] \\
\hline $\mathrm{SiC} / \mathrm{EP}$ & $12-12.4$ & 80 & $\sim 17$ & - & [S7] \\
\hline $\mathrm{TiC} / \mathrm{EP}$ & $12-18$ & 70 & $\sim 17-22$ & - & [S8] \\
\hline Hollow- $\mathrm{Al}_{2} \mathrm{O}_{3} / \mathrm{EP}$ & $18-30$ & 20 & $\sim 2.9-3.0$ & - & [S9] \\
\hline $\mathrm{Al}_{2} \mathrm{O}_{3} / \mathrm{EP}$ & $18-30$ & 27 & $\sim 3.1-3.2$ & - & [S9] \\
\hline BNNSs/EP & $12-40$ & 90 & $3.15-4.16$ & $0.03-0.25$ & This work \\
\hline
\end{tabular}


a

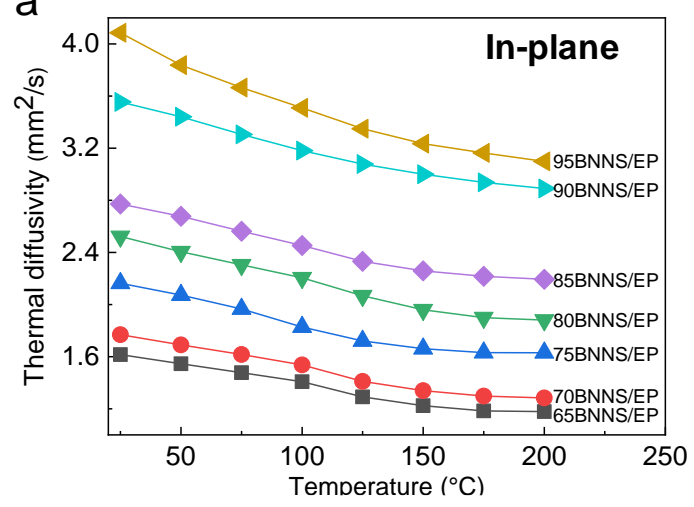

b

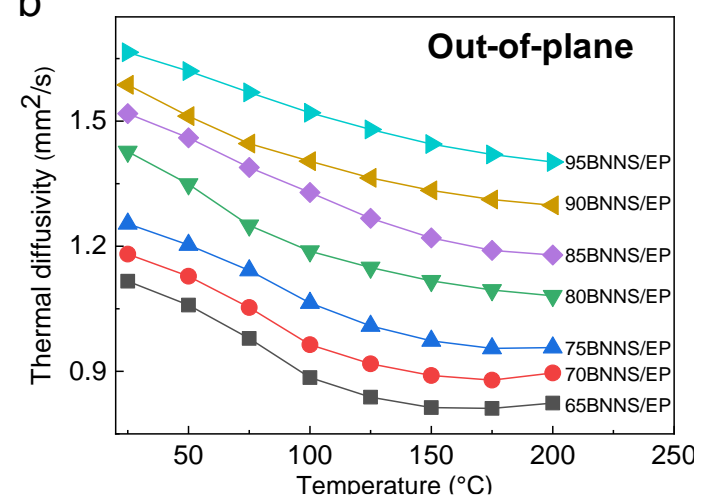

Figure S20. Temperature-dependent thermal diffusivities of the BNNSs/EP nanocomposite with different BNNSs contents measured in the in-plane (a) and out-ofplane (b) directions. 
Table S3. Comparison of thermal conductivities of the other BN based polymer composites with our BNNSs/EP bulk composites.

\begin{tabular}{|c|c|c|c|c|c|}
\hline \multirow{2}{*}{ Composites } & \multirow{2}{*}{$\begin{array}{c}\text { BN } \\
\text { Loading } \\
\text { (wt.\%) }\end{array}$} & \multicolumn{2}{|c|}{$\begin{array}{l}\text { Thermal conductivity } \\
(\mathrm{W} / \mathrm{m} \cdot \mathrm{k})\left(25^{\circ} \mathrm{C}\right)\end{array}$} & \multirow{2}{*}{$\begin{array}{l}\mathrm{TC}_{\text {in-plane }} / \\
\mathrm{TC}_{\text {out-of-plane }}\end{array}$} & \multirow{2}{*}{ Refs. } \\
\hline & & $\mathrm{TC}_{\text {in-plane }}$ & $\begin{array}{c}\mathrm{TC}_{\text {out-of- }} \\
\text { plane }\end{array}$ & & \\
\hline $\mathrm{PEI} / \mathrm{PI} / \mathrm{BN}$ & 60 & $\sim 3.3$ & $\sim 1.7$ & $\sim 1.9$ & [S10] \\
\hline $\mathrm{PEI} / \mathrm{BN}$ & 60 & $\sim 2.6$ & $\sim 0.8$ & $\sim 3.3$ & [S10] \\
\hline $\mathrm{PI} / \mathrm{BN}$ & 30 & $\sim 2.8$ & $\sim 0.7$ & $\sim 4.0$ & [S11] \\
\hline CNF/BNNSs & 50 & $\sim 7$ & $\sim 0.7$ & $\sim 10.0$ & {$[\mathrm{~S} 12]$} \\
\hline PDMS/PVA/BNNSs & 23.3 & $\sim 1.8$ & $\sim 0.6$ & $\sim 3.0$ & [S13] \\
\hline EP/BNNSs & 32 & $\sim 6.5$ & $\sim 0.7$ & $\sim 9.3$ & [S14] \\
\hline 3D-BNNSs/EP & 16 & $\sim 2.9$ & $\sim 2.4$ & $\sim 1.2$ & {$[\mathrm{~S} 15]$} \\
\hline $\mathrm{PVDF} / \mathrm{BNNSs}$ & 33 & $\sim 5.0$ & $\sim 0.5$ & $\sim 10.0$ & [S16] \\
\hline BNNSs/EP & 90 & $\begin{array}{l}6.6 \pm 0.1 \\
\left(25^{\circ} \mathrm{C}\right)\end{array}$ & $2.6 \pm 0.08$ & $\sim 2.5$ & This work \\
\hline BNNSs/EP & 90 & $\begin{array}{l}8.4 \pm 0.2 \\
\left(200^{\circ} \mathrm{C}\right)\end{array}$ & $\begin{array}{l}3.5 \pm 0.1 \\
\left(200^{\circ} \mathrm{C}\right)\end{array}$ & $\sim 2.4$ & This work \\
\hline
\end{tabular}



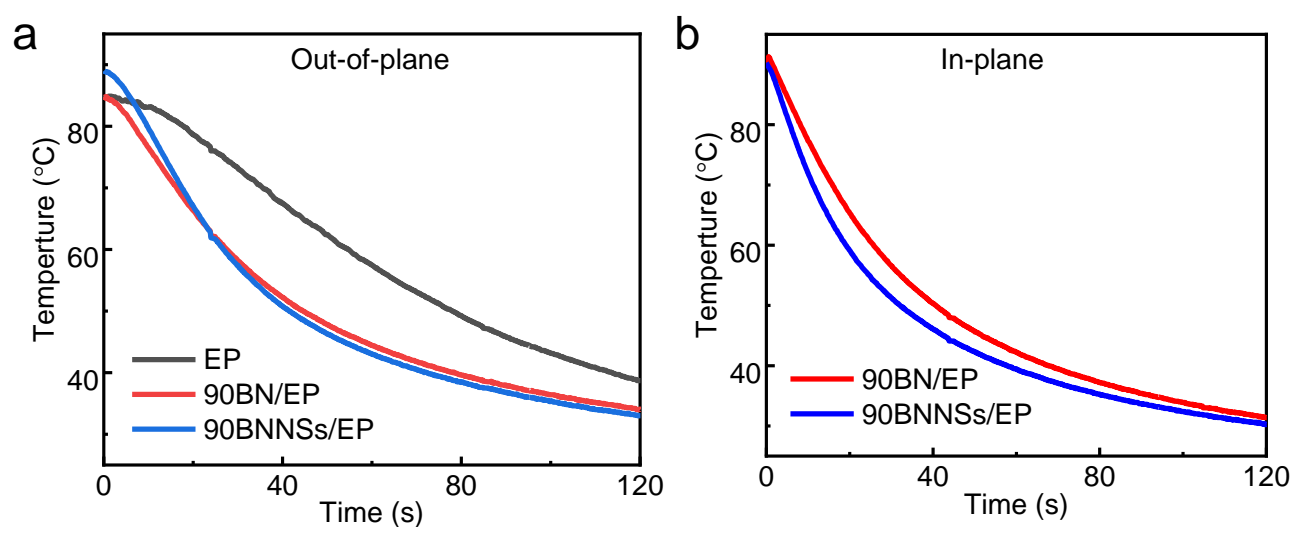

Figure S21. The detected temperatures as a function of the cooling time were plotted based on the data from the in-plane and the out-of-plane infrared thermal images in 0 $120 \mathrm{~s}$. 


\section{REFERENCES}

S1. Wang, J.; Wang, J.; Xu, R.; Sun, Y.; Zhang, B.; Chen, W.; Wang, T.; Yang, S.

Enhanced Microwave Absorption Properties of Epoxy Composites Reinforced with $\mathrm{Fe}_{50} \mathrm{Ni}_{50}$-Functionalized Graphene. J. Alloys Compd. 2015, 653, 14-21.

S2. Nwigboji, I. H.; Ejembi, J. I.; Wang, Z.; Bagayoko, D.; Zhao, G.-L. Microwave Absorption Properties of Multi-Walled Carbon Nanotube (Outer Diameter 20-30 nm)Epoxy Composites from 1 to $26.5 \mathrm{GHz}$. Diamond Relat. Mater. 2015, 52, 66-71.

S3. Wang, Z.; Zhao, G.-L. Microwave Absorption Properties of Carbon NanotubesEpoxy Composites in a Frequency Range of 2-20 GHz. Open J. Compos. Mater. 2013, $3,17-23$.

S4. Lee, S.-E.; Choi, O.; Hahn, H.T. Microwave Properties of Graphite Nanoplatelet/Epoxy Composites. J. Appl. Phys. 2008, 104, 033705.

S5. Al-Ghamdi, A. A.; El-Tantawy, F. Electromagnetic Wave Shielding and Microwave Absorbing Properties of Hybrid Epoxy Resin/Foliated Graphite Nanocomposites. $J$. Appl. Polym. Sci. 2013, 127, 2227-2234.

S6. Wang, Y.; Liu, X.; Jiang, Y.; Lan, X.; Wang, L. Preparation and MicrowaveAbsorbing Properties of Some Non-Circular SiC Fibers. Funct. Mater. Inf. 2011, 8, 2024.

S7. Kumar, A.; Agarwala, V.; Singh, D. Effect of Milling on Dielectric and Microwave Absorption Properties of SiC Based Composites. Ceram. Int. 2013, 40, 1797-1806.

S8. Wang, Y.; Luo, F.; Zhou, W.; Zhu, D. Dielectric and Electromagnetic Wave Absorbing Properties of TiC/Epoxy Composites in The GHz Range. Ceram. Int. 2014, 
40, 10749-10754.

S9. Utsuno, S.; Matsumura, K.; Kagawa, Y. Potential of Hollow $\mathrm{Al}_{2} \mathrm{O}_{3}$ Nanoparticles for Reducing Dielectric Properties of A12O3-Epoxy Matrix Composites in Microwave Frequency Range. Microwave Opt. Technol. Lett. 2010, 52, 1069-1072.

S10. Lee, H. L.; Kwon, O. H.; Ha, S. M.; Kim, B. G.; Kim, Y. S.; Won, J. C.; Kim, J.;

Choi, J. h.; Yoo, Y. Thermal Conductivity Improvement of Surface-Enhanced Polyetherimide (PEI) Composites Using Polyimide-Coated $h$-BN Particles. Phys. Chem. Chem. Phys. 2014, 16, 20041-20046.

S11. Wang, H.; Ding, D.; Liu, Q.; Chen, Y.; Zhang, Q. Highly Anisotropic Thermally Conductive Polyimide Composites via The Alignment of Boron Nitride Platelets. Composites, Part B 2019, 158, 311-318.

S12. Wu, K.; Fang, J.; Ma, J.; Huang, R.; Chai, S.; Chen, F.; Fu, Q. Achieving a Collapsible, Strong, and Highly Thermally Conductive Film Based on Oriented Functionalized Boron Nitride Nanosheets and Cellulose Nanofiber. ACS Appl. Mater. Interfaces 2017, 9, 30035-30045.

S13. Chen, J.; Huang, X.; Sun, B.; Wang, Y.; Zhu, Y.; Jiang, P. Vertically Aligned and Interconnected Boron Nitride Nanosheets for Advanced Flexible Nanocomposite Thermal Interface Materials. ACS Appl. Mater. Interfaces 2017, 9, 30909-30917.

S14. Han, J.; Du, G.; Gao, W.; Bai, H. An Anisotropically High Thermal Conductive Boron Nitride/Epoxy Composite Based on Nacre-Mimetic 3D Network. Adv. Funct. Mater. 2019, 29, 1900412.

S15. Zeng, X.; Yao, Y.; Gong, Z.; Wang, F.; Sun, R.; Xu, J.; Wong, C. Ice-Templated 
Assembly Strategy to Construct 3D Boron Nitride Nanosheets Networks in Polymer Composites for Thermal Conductivity Improvement. Small 2015, 11, 6205-6213.

S16. Chen, J.; Huang X.; Sun, B.; Jiang, P. Highly Thermally Conductive Yet Electrically Insulating Polymer/Boron Nitride Nanosheets Nanocomposite Films for Improved Thermal Management Capability. ACS Nano 2019, 13, 337-345. 